IFN Working Paper No. 789, 2009

\title{
Paying to Remove Advertisements
}

\author{
Joacim Tåg
}




\title{
Paying to Remove Advertisements
}

\author{
Joacim Tåg* \\ Research Institute of Industrial Economics (IFN) \\ P.O. Box 55665, SE-102 15 Stockholm, Sweden. \\ E-mail: joacim.tag@ifn.se
}

February 13, 2009

\begin{abstract}
Media firms sometimes allow consumers to pay to remove advertisements from an advertisement-based product. We formally examine an ad-based monopolist's incentives to introduce this option. When deciding whether to introduce the option to pay, the monopolist compares the potential direct revenues from consumers with lost advertising revenues from not intermediating those consumers to advertisers. If the option is introduced, the media firm increases advertising quantity to make the option to pay more attractive. This hurts consumers, but benefits the media firm and advertisers. Total welfare may increase or decrease. Perhaps surprisingly, more annoying advertisements may lead to an increase in advertising quantity.

Keywords: Advertising, damaged goods, media markets, price discrimination, twosided markets, vertical differentiation.

JEL-codes: D42, L15, L59, M37
\end{abstract}

\section{Introduction}

There are many recent examples of cases where firms allow consumers to pay to remove advertisements from an otherwise advertising-based product. For example, Slashdot.org allows users to pay $\$ 5$ for 1000 ad-free pages. ${ }^{1}$ Gamespot.com offers a monthly subscription at $\$ 3.33$ that gives the subscriber access to "The GameSpot experience without intrusive ads or commercials". 2 The Walt Disney Company (and many others) offers TV series for purchase through the iTunes store at $\$ 1.99$ per episode. A free alternative with advertisements is available on their homepage or by watching the show on TV. ${ }^{3}$ We 7 offers music downloads

*This research was partly conducted while the author was holding a GS Fellowship position awarded by the Finnish Doctoral Programme in Economics, partly while being a visiting scholar at Leonard N. Stern School of Business, New York University (supported by an ALSA-Fulbright grant and the Commerce and Industry Fund at Hanken) and partly within the Gustaf Douglas Research Program on Entrepreneurship at the Research Institute of Industrial Economics. I would like to thank Jay Pil Choi, Tore Nilssen, Lars Sørgard, Rune Stenbacka, Tuomas Takalo, Otto Toivanen, David Waterman, two anonymous referees, and numerous colleagues and workshop participants for very helpful discussions, comments and suggestions.

${ }^{1}$ http://slashdot.org/faq/subscriptions.shtml (accessed December 2008).

${ }^{2}$ http://www.gamespot.com (accessed December 2008).

${ }^{3}$ See http://www.apple.com/itunes/ (accessed December 2008). Some cable television companies also offer subscription services for digital video recorders that can be set to automatically remove advertisements from recorded shows. 
with ads attached to the beginning of the song for free or at a fee without the ads. ${ }^{4}$ There are also companies such as Ultramercial that allow consumers to "pay" for premium content on websites by watching a series of interactive advertisements. ${ }^{5}$

These examples highlight a strategy where media providers practice second-degree price discrimination by offering two versions differing in advertising quantity. The strategy is easily followed for online media firms, since advertisements are easily separable from content. In general, there has been a shift in the distribution costs of content, implying that media firms now find it easier to distribute multiple versions of their content, which is in stark contrast to traditional print and broadcasting media where the distribution costs can be high. For example, technologies such as streaming video over the Internet and enhanced compression techniques make it easy to charge consumers for an ad-free version of television shows.

But what are the incentives of media firms to introduce the option to pay to remove advertisements? And what are the welfare implications? In this paper, we aim at answering these questions. They are important, as the provision of programming and advertising in the broadcasting industry has been subjected to a considerable degree of attention from regulators. For example, advertising quantity is regulated in several European countries. As an increasing amount of advertising expenditures moves online, the implications of newly available strategies, such as charging consumers for the removal of advertisements, may become important in policy discussions.

We set up a stylized model of a monopolist media firm entirely financed by advertisements. Consumers are assumed to dislike advertisements, and we model bundling advertisements with a good as reducing the perceived quality of the good ("damaging" the good). Then, we study the incentives of the firm to introduce an ad-free version at a positive price. Advertising quantity, and hence the quality of the free advertising-based version, is endogenous. We show that the monopolist will introduce the option if the disutility from advertisements experienced by consumers is sufficiently high in relation to advertisers' profit margins from reaching users. We highlight three results.

First, if the option to pay is introduced, there is an increase in advertising quantity. The media firm compares the revenue from paying consumers with the potential advertising revenue that can be earned by mediating those consumers to advertisers. Because the free advertising-based product cannibalizes on the sales of a pay version without advertisements, the media firm optimally increases advertising quantity in the free version when the option to pay to remove advertisements is introduced. This result gives the empirical implication that observed advertising quantity should be higher if the option to pay to remove advertisements is available.

Second, advertising quantity in the free version may be increasing in the disutility caused by advertisements. The reason is that increasing advertising quantity is a more effective way of reducing the perceived quality of the free version when consumers' disutility from advertisements is high. Hence, an empirical implication is that advertisements should be more annoying and intrusive if the option to pay to remove advertisements is present.

\footnotetext{
${ }^{4}$ See http://www.we7.com (accessed December 2008).

${ }^{5}$ See http://www.ultramercial.com (accessed December 2008).
} 
Third, regarding the welfare effects of introducing the option to pay, we show that consumers' welfare decreases, while media firm profits and advertiser profits increase. Consumer welfare decreases because consumers using the free version see more advertisements, and consumers paying to remove advertisements pay a price that causes more disutility than what advertisements would have caused had the option to pay not been available.

Our paper is related to the literature on price discrimination in media markets, to the literature on quality segmentation and damaged goods and to the recent literature on twosided markets.

We contribute to the literature on price discrimination in media markets by analyzing the case of second-degree price discrimination by introducing the option to pay to remove advertisements from an otherwise ad-based free product. Previous analyses in the media market literature have focused on welfare issues related to pay-per-view versus free airing of outstanding events (such as boxing matches). Price discrimination is an issue since the media firm can require consumers to pay to watch the event live and then air it for free a day later. This is the setup in Holden (1993) which concludes that consumers are harmed by the possibility of pay-per-view. Hansen and Kyhl (2001) consider a slightly different setup where the pay-per-view version contains advertisements and a free version is not available. They analyze how a ban on pay-per-view affects welfare. They find that consumer welfare is enhanced by a ban, but the overall impact on welfare is ambiguous. A recent addition to the literature is Anderson and Gans (2008), who examine the impact on broadcaster behavior when consumers adopt advertising avoidance technologies. ${ }^{6}$ They show that advertising quantity could increase, as the remaining consumers are less averse to advertising. As a result, overall welfare and program quality could decrease and programming would be tailored to appeal to a broader range of viewers. Price discrimination in media markets has also attracted some attention in the marketing literature. Prasad, Mahajan, and Bronnenberg (2003) analyze the incentives to price discriminate when consumers are of two given types and a media firm may offer two versions differing in advertising quantity and price. They show that offering two versions (price discrimination) tends to be optimal in most cases.

We also contribute to the literature on intertemporal and product quality segmentation, mainly in relation to the literature on damaged goods. ${ }^{7}$ Deneckere and McAfee (1996) examine costly reduction of quality ("damaging" an already developed product) in order to obtain a lower quality version. Chiang and Spatt (1982) study quality reduction by bundling wait time and Salop (1977) study quality reduction by bundling search costs with the product. In our setup, quality is reduced by bundling advertisements with the product. Compared to degrading quality by other means, "damaging" goods with advertisements is different since it generates a new source of revenues. This gives the firm an additional incentive to "damage" its goods. Our paper also relates to the vertical product differentiation literature (e.g. Shaked and Sutton (1982) and Greenstein and Ramey (1998)) in that we study the incentives to bring out a higher quality product at a fee in addition to a free, but lower quality, advertising-based product.

\footnotetext{
${ }^{6}$ See also Wilbur $(2008 \mathrm{a}, \mathrm{b})$ for empirical results relating to the use of advertising avoidance technologies.

${ }^{7}$ For a good treatment of damaged goods and versioning, see Varian (2001).
} 
Finally, we also contribute to the literature on two-sided media markets, ${ }^{8}$ and to the two-sided market literature in general, ${ }^{9}$ by studying second-degree price discrimination in a two-sided market setting. A crucial difference between second-degree price discrimination in one-sided markets as compared to the current setup using a two-sided market approach is that the price and the quality of the lower quality version depend on the price for advertising space set on the other side of the market. In a one-sided market, prices are set given the quality of the different versions. Here, as prices for the versions change, so does the attractiveness of advertising space to advertisers. This, in turn, affects the optimal price for advertising space and the amount of advertising determining the quality of the lower quality version.

We have structured the paper in the following way. In section 2 , we first set up a model of a monopolist media firm offering an advertising-supported product (subsection 2.2) and then examine the incentives of the monopolist to introduce a pay version of the product without advertisements (subsection 2.3). Then, we study the welfare implications of allowing consumers to pay to remove advertisements (subsection 2.4) and discuss the model and possible extensions (section 3). The final section concludes the paper.

\section{The Model}

\subsection{Setup}

Consider a monopolist media firm that has developed a good of the intrinsic quality level $q_{p}=$ $v>0$. The media firm can be a broadcaster, a magazine, a software firm, a website or any other kind of firm that can embed advertisements in its product. The fixed costs related to the development of this product are sunk and duplication carries small or zero costs. Initially, the media firm is advertising-based and does not charge consumers. However, consumers dislike advertisements. The perceived quality of the product accounting for disutility from advertisements is $q_{a}=v-\gamma a>0$, where $a \in[0,1]$ is advertising quantity and $\gamma<v$ is a measure of how annoying advertisements are perceived to be. ${ }^{10}$ Consumers, a continuum of mass $N$ with unit demand, are heterogeneous with respect to their marginal valuation of quality denoted by $\theta$. The distribution of $\theta$ is uniform on the unit interval. Hence, consumer $i$ values the advertising-based media firm's product at $u_{i}=\theta_{i} q_{a}=\theta_{i}(v-\gamma a)$.

The specific dependence of quality on advertising used here allows consumers to be heterogeneous both in terms of intrinsic product quality and the impact of advertising on their utility. ${ }^{11}$ This is consistent with an interpretation that advertisements degrade the perceived

\footnotetext{
${ }^{8}$ E.g. Anderson and Coate (2005), Crampes, Haritchablet and Jullien (2005) and Gabzewicz, Laussel and Sonnac (2004).

${ }^{9}$ E.g. Caillaud and Jullien (2003), Rochet and Tirole (2003) and Armstrong (2006).

${ }^{10}$ That consumers dislike advertising is in line with Holden (1993), Hansen and Kyhl (2001), Prasad, Mahajan and Bronnenberg (2003) and Anderson and Gans (2008). For the markets we consider, this seems to be a reasonable assumption since consumers are observed to be willing to pay to remove advertisements and thus, they clearly reveal a preference for consuming the product without ads.

${ }^{11} \mathrm{~A}$ heterogeneous impact of advertising on utility is an important difference between our model and the analyses in Holden (1993) and Hansen and Kyhl (2001). Heterogeneous aversion to advertising is part of the analysis in Prasad, Mahajan and Bronnenberg (2003), but they do not consider to what extent advertisements have an impact on utility. Essentially, the assumption is that $\gamma=1$. Moreover, they only consider two consumer types $\left(\theta_{H}\right.$ and $\left.\theta_{L}\right)$.
} 
quality of the product (they "damage" the product). It seems reasonable to assume that consumers who value quality more also dislike advertisements more. First, in many cases, advertising takes up space, which reduces the amount of content. The reduction of content is more important for consumers who value content highly. Second, advertising requires attention from consumers. Consumers who value quality highly might have a higher opportunity cost of time and hence, dislike advertisements more. Note, though, that this assumption also implies that all consumers will use the media firm's product since $q_{a}>0$ and the product is free. We retain this assumption as it simplifies our analysis, although note that it is not a standard assumption in the literature.

Advertising quantity, $a$, hence also $q_{a}$, is endogenous in the model. Advertisers, a continuum with mass 1 , are monopoly producers of new goods. ${ }^{12}$ Advertising fills the role of informing consumers about the prices and characteristics of their goods. ${ }^{13}$ Each advertiser has developed a new good characterized by its type $\sigma$ uniformly distributed on the unit interval. The type of good indicates its purchase probability after being advertised. Goods of a higher type are more likely to be bought after being advertised. The profit margin on the goods sold by the advertisers is $s$. Advertiser $j$ is willing to pay a maximum price of $\sigma_{j} s n N$ to place an advertisement in the media firm's product, where $n$ is the fraction of consumers viewing the advertisements attached to the media firm's product. Advertiser $j$ profits from advertising according to $\sigma_{j} s n N-p_{a}$ if advertising and 0 otherwise. Here, $p_{a}$ denotes the price charged by the media firm for advertising space. The advertiser who is indifferent between advertising and not has $\sigma_{a}=\frac{p_{a}}{s n N}$, thus implying that the mass of advertising advertisers, hence advertising quantity, is $a=1-\frac{p_{a}}{s n N}$.

\subsection{An Advertising-based Media Firm}

A media firm that is entirely advertising-based faces the decision of optimally setting the price for advertising space. Since $n=1$, demand for advertising space is $a\left(p_{a}\right)=\left(1-\frac{p_{a}}{s N}\right)$ for $p_{a} \in[0, N s], a\left(p_{a}\right)=0$ for $p_{a}>N s$ and $a\left(p_{a}\right)=1$ otherwise. The media firm's profit function is given by

$$
\Pi_{A}\left(p_{a}\right)=p_{a} a\left(p_{a}\right) .
$$

The firm chooses the price for ad-space so as to maximize profits.

Lemma 1 When the media firm is advertising-based, the profits are $\Pi_{A}=\frac{s N}{4}$ and the advertising quantity is $a_{a}=\frac{1}{2}$.

Proofs to all lemmas and propositions are found in the Appendix. When the firm is advertising-based, all consumers use the product and view advertisements. The media firm can charge more for ad-space if advertisers' profit margins $(s)$ are higher or if there are more consumers $(N)$ in the market viewing the advertisements. How annoying consumers perceive advertisements to be $(\gamma)$ does not affect prices or advertising quantity since $q_{a}>0$ (the market is covered).

\footnotetext{
${ }^{12}$ So $N>1$ implies that there are relatively more consumers than advertisers.

${ }^{13}$ For a discussion of the different roles of advertising see, for example, Bagwell (2007). The advertising market used in this model is partly adopted from Anderson and Coate (2005).
} 

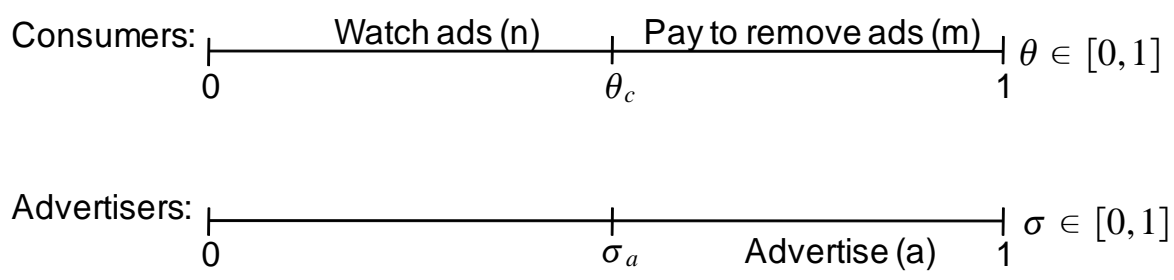

Figure 1: Consumers either watch advertisements or pay to remove them. Advertisers either advertise or not.

\subsection{Introducing the Option to Pay to Remove Advertisements}

Let us now examine the media firm's incentive to introduce the option of paying to remove advertisements, i.e. the incentive to bring out a higher quality product not "damaged" by advertisements but at a positive price $p_{c}$.

Let $\theta_{c}$ denote the consumer who is indifferent between paying to remove advertisements and using the advertising-based version for free. Given prices, it must then be the case that consumers with $\theta \in\left[\theta_{c}, 1\right]$ pay while consumers with $\theta \in\left[0, \theta_{c}\right]$ use the free version. The location of the indifferent consumer can be obtained from the indifference equation $\theta_{c} q_{p}-p_{c}=\theta_{c} q_{a}$ or

$$
\theta_{c} v-p_{c}=\theta_{c}(v-\gamma a) .
$$

Solving for $\theta_{c}$, we obtain $\theta_{c}=\frac{p_{c}}{\gamma a}$. Demand for the advertising-based version is then given by $N n\left(p_{c}, a\right)=N\left(\frac{p_{c}}{\gamma a}\right)$ for $p_{c} \in[0, \gamma a]$, by $N$ for $p_{c}>\gamma a$ and by 0 otherwise. Demand for the feebased version is $N m\left(p_{c}, a\right)=N\left[1-n\left(p_{c}, a\right)\right]$. All consumers acquire the media firm's product, but only fraction $n$ views the ads. Demand for ad-space is, as above, $a\left(p_{a}, n\right)=\left(1-\frac{p_{a}}{s n N}\right)$ for $p_{a} \in[0, s n N], 0$ for $p_{a}>s n N$ and 1 otherwise. See Figure 1 for an illustration.

The timing is the following. First, the media firm sets prices $p_{c}$ and $p_{a}$. Then, consumers and advertisers observe these prices and make their purchase and participation decisions. This timing captures a setting where consumers and advertisers arrive in an alternated fashion, so that neither consumers nor advertisers move first. To account for the fact that the demand for ad-space depends on the demand for the ad-based version and vice versa, we assume that consumers form fulfilled expectations regarding the participation of advertisers and that advertisers form fulfilled expectations regarding the participation of users. Hence, we simultaneously solve $n=\frac{p_{c}}{\gamma a}$ and $a=1-\frac{p_{a}}{s n N} \cdot{ }^{14}$ This system has the solutions $n\left(p_{c}, p_{a}\right)=\frac{p_{a}}{s N}+\frac{p_{c}}{\gamma}$ and $a\left(p_{c}, p_{a}\right)=\frac{s N p_{c}}{s N p_{c}+p_{a} \gamma}$, which give the share of consumers viewing the advertisements and demand for ad-space as functions of the price for removing advertisements and the price for ad-space. Demand for the advertising-based version is $N n\left(p_{c}, p_{a}\right)$ and demand for the fee-based version is $N\left[m\left(p_{c}, p_{a}\right)\right]=N\left[1-n\left(p_{c}, p_{a}\right)\right]$.

\footnotetext{
${ }^{14}$ Alternative variations of the model could have consumers first committing to purchase the advertisingbased version and then advertisers deciding on participation or, alternatively, have advertisers first committing to advertise and then consumers making their purchase decisions. Such modifications of the model change the expressions for demand since one side of the market observes participation on the other side, but the analysis is otherwise unaffected.
} 
The media firm sets the prices to maximize

$$
\Pi_{F+A}=N\left[m\left(p_{c}, p_{a}\right)\right] p_{c}+a\left(p_{c}, p_{a}\right) p_{a}
$$

subject to the constraints that $0 \leq p_{a} \leq s N n\left(p_{c}, p_{a}\right)$ and $0 \leq p_{c} \leq \gamma a\left(p_{c}, p_{a}\right)$. Solving this problem for an interior solution gives the main proposition of the paper.

Proposition 1 The option to pay to remove advertisements is introduced if $\gamma>\frac{1}{2}$ s since an interior solution is obtained for $\left.\frac{s}{\gamma} \in\right] \frac{1}{2}, 2\left[\right.$. The profits are $\Pi_{F+A}=N \frac{(s+\gamma)^{2}(2 \gamma-s)}{27 s \gamma}$ and are increasing in $\gamma$ and $s$. The profits from consumers are increasing in $\gamma$ and decreasing in $s$. The profits from advertisers are decreasing in $\gamma$ and increasing in s. Advertising quantity is $a=\frac{1}{3}+\frac{\gamma}{3 s}>\frac{1}{2}$. It is higher than when the firm is entirely ad-based and it is increasing in $\gamma$.

This proposition shows that the media firm makes its decision to introduce the option to pay to remove advertisements based on if the additional revenues from paying consumers are sufficient to offset the losses from not mediating those consumers to advertisers. The revenues from paying consumers increase if advertisements cause more disutility ( $\gamma$ increases). The revenues from mediating those consumers to advertisers increase if advertisers' profit margins $(s)$ increase. Hence, it is the relation between $\gamma$ and $s$ that is of importance.

But the media firm also controls advertising quantity through the price for advertising space. When the option to pay to remove advertisements is introduced (a product of quality $q_{p}=v$ ), the media firm has an incentive to induce more consumers to pay to remove advertisements. It can reduce the cannibalizing effect of the free advertising-based version (of quality $q_{a}=v-\gamma a$ ) on the pay version by reducing $p_{a}$ and thereby increasing $a$. This leads to a reduction in $q_{a}$ and more consumers thus choose to pay to obtain $q_{p}$. This result is similar to the results from standard second-degree price discrimination models with endogenous quality levels (e.g. Mussa and Rosen (1978)). The lower quality version of the product gets a quality that is distorted downwards to allow for a higher price of the high-quality version. The incentive to distort quality downwards increases as $\gamma$ increases since the same reduction in $p_{a}$ (leading to an increase in $a$ ) has a larger effect on perceived quality and thereby on the revenues from consumers. Hence, and perhaps surprisingly, advertising quantity is increasing in the disutility advertising causes consumers.

Finally, the proposition provides two empirically testable predictions. First, when paying to remove advertisements is possible, advertising quantity in the free version should be higher than when it is not. Second, advertisements should be more annoying and intrusive if the option to pay to remove advertisements is present. There seems to be some anecdotal evidence of this result. As mentioned by Prasad, Mahajan, and Bronnenberg (2003), Slashdot.org increased the number of advertisements displayed in connection with introducing the option to pay to remove advertisement. The same seems to be true for Gamespot.com. Compared to other sites operated by CNET Networks, Gamespot.com seems to have the most annoying and intrusive advertisements. It is one of the sites in their portfolio that allows consumers to pay to get rid of the advertisements. 


\subsection{Welfare Implications}

What are the welfare implications of introducing the option of paying to remove advertisements? Suppose that we consider total surplus defined as $T S=C S^{F}+C S^{A}+A S+\Pi$, where $C S^{F}$ is the consumer surplus for consumers using the fee based version, $C S^{A}$ the consumer surplus for consumers using the advertising-based version, $A S$ is advertiser surplus and $\Pi$ are media firm profits. Media firm profits are determined above and the remaining parts are defined as:

$$
\begin{aligned}
C S^{F}\left(\theta_{c}, p_{c}\right) & =N \int_{\theta_{c}}^{1} \theta v-p_{c} d \theta \\
C S^{A}\left(\theta_{c}, p_{c}, a\right) & =N \int_{0}^{\theta_{c}} \theta(v-\gamma a) d \theta \\
A S\left(\sigma_{a}, p_{a}, n\right) & =\int_{\sigma_{a}}^{1} \sigma s n N-p_{a} d \sigma .
\end{aligned}
$$

By substituting optimal values of $p_{c}, \theta_{c}, a, \sigma_{a}$ and $n$, we obtain the following proposition.

Proposition 2 Introducing the option to pay to remove advertisements reduces the consumer surplus for

(i) paying consumers: $\Delta C S^{F}=\frac{\left(\frac{s}{\gamma}-2\right)^{3} N \gamma}{108 \frac{s}{\gamma}}<0$, and for

(ii) consumers still watching advertisements: $\Delta C S^{A}=\frac{\left(\frac{s}{\gamma}-2\right)\left(1+\frac{s}{\gamma}\right)^{2} N \gamma}{108 \frac{s}{\gamma}}<0$.

The advertiser and media firm surplus increases. The total surplus decreases if $\frac{s}{\gamma} \in$ ]$\left.\frac{1}{2}, \frac{25+3 \sqrt{41}}{32}\right]$ and increases if $\frac{s}{\gamma} \in\left[\frac{25+3 \sqrt{41}}{32}, 2[\right.$.

The consumer surplus decreases for consumers using the free advertising-based version since advertising quantity is increased when the option to pay to remove advertisements is available. Consumers paying to remove advertisements are also worse off since the price they pay for removing advertisements is higher than the disutility advertisements would have caused them had this option not been available. The media firm obviously benefits since it could always choose not to introduce this option. Advertisers benefit because the price for advertising must decrease for advertising quantity to increase. Hence, the impact on total welfare depends on the relative sizes of gains to the media firm and advertisers, versus the losses in consumer surplus. ${ }^{15}$

Note that one potential effect on welfare of introducing the option to pay to remove advertisements might be missing from our setup due to market coverage. If consumers varied in their dislike of advertisements, $\gamma$, some consumers might not use the media firm's product when the media firm is ad-based only. Then, there is a potential positive effect on the consumer surplus of allowing consumers to pay to remove advertisements, since some of these consumers might use it if they could pay to remove the advertisements.

\footnotetext{
${ }^{15}$ The result that consumers are harmed and that the impact on overall welfare is ambiguous is in line with the analyses of Holden (1993) and Hansen and Kyhl (2001).
} 


\section{Discussion and Extensions}

\subsection{An Entirely Fee-Based Media Firm}

In the above analysis, the media firm did not have the option to stop selling the free advertisement-based version of its product. The media firm might have an incentive for this if the intrinsic quality of the product, $v$, is sufficiently large. To see this, suppose that the media firm is entirely fee-based and offers no advertising-based product. Let the consumer who is indifferent between buying and not buying the fee-based product be of type $\theta_{f}$. Then, consumers of type $\theta \in\left[\theta_{f}, 1\right]$ buy the product. The location of $\theta_{f}$ is given by

$$
\theta_{f} v-p_{f}=0
$$

Demand for the fee-based product is then $N m\left(p_{f}\right)=N\left(1-\theta_{f}\right)=N\left(1-\frac{p_{f}}{v}\right)$ for $p_{f} \in[0, v]$, $N m\left(p_{f}\right)=0$ for $p_{f}>v$ and $N m\left(p_{f}\right)=N$ otherwise. The media firm's profit function is

$$
\Pi_{F}\left(p_{f}\right)=p_{f} N m\left(p_{f}\right)
$$

The media firm chooses the price to maximize profits.

Lemma 2 When the media firm is fee-based, the price for the product is $\frac{v}{2}$ and the profits are $\Pi_{F}=N \frac{v}{4}$.

When the media firm is fee-based, a higher quality product implies higher profits. An increase in the number of consumers has the same effect. ${ }^{16}$

Using this lemma, we can now compare profit levels when being entirely advertisementbased, allowing for paying to remove advertisements and having no advertisements. Then, we obtain the following proposition:

Proposition 3 For $\frac{s}{\gamma} \in\left[0, \frac{1}{2}\right]$, only a fee-based version is optimal. For $\left.\frac{s}{\gamma} \in\right] \frac{1}{2}, 2[$ and $v<$ $v^{*}$ where $v^{*}$ is such that $\Pi_{F}-\Pi_{A+F}=N \frac{v^{*}}{4}-N \frac{(\gamma+s)^{2}}{27 \gamma s}=0$, a fee-based version and an advertising-based version should be made available so that consumers can pay to remove advertisements. If $\left.\frac{s}{\gamma} \in\right] \frac{1}{2}, 2\left[\right.$ and $v \geq v^{*}$, only a fee-based version is optimal. For $\frac{s}{\gamma} \in[2, \infty[$ and $v<v^{* *}$, where $v^{* *}$ is such that $\Pi_{F}-\Pi_{A}=N \frac{v^{* *}}{4}-N \frac{s}{4}=0$, the media firm should be purely advertising-based. If $\frac{s}{\gamma} \in\left[2, \infty\left[\right.\right.$ and $v \geq v^{* *}$, only a fee-based version is optimal.

The intuition for the above proposition is similar to the intuition for proposition 1 with the added possibility of not taking on any advertising. Consumers' willingness to pay for a fee-based version is related to how annoying advertisements are $(\gamma)$. Advertisers' willingness to pay for ad-space is related to their profits for reaching a consumer $(s)$. Hence, the relation between the two variables determines on what source of revenues the media firm should focus.

\footnotetext{
${ }^{16}$ As consumers are heterogeneous with respect to quality, it might be asked whether the media firm would find it optimal to price discriminate by offering two versions of the product, $v_{H}$ and $v_{L}$, such that $v_{H}>v_{L}$, but no version with advertisements. It can be shown that this kind of price discrimination is not optimal. The reason is that the marginal costs are zero and not affected by the quality level. Hence, there is no reduction in marginal costs when quality is reduced. It is then optimal to only offer one version (with the current utility specification).
} 
However, it may be the case that simply selling the product to consumers and not involving advertisers is optimal. This is the case if product quality $(v)$ is sufficiently high. Then, because a free advertising-based version cannibalizes on the sales of the product without advertisements, only offering a fee-based version is optimal.

\subsection{On Advertisers' Profit Margins}

Another possible extension of this framework would be to consider the case where the profit margins of the advertisers are dependent on consumers' valuation of quality, $\theta$. Relaxing this assumption would have at least two implications.

First, a formal model of how advertisers price their goods would be needed. Their pricing decision would be dependent on how many consumers use the ad-based version offered by the media firm and hence, on the price for removing advertisements. ${ }^{17}$ Second, consumers would be left with some surplus from purchasing advertisers' goods and hence, have to balance the disutility from having advertisements with possible gains from being informed about a useful product generating utility.

\subsection{Market Coverage, Product Quality and Variety}

An important welfare aspect with regards to media industries involves how the option of paying to remove advertisements affects the media firm's dynamic incentives to invest in increasing the fixed product quality $v$. Since we have assumed that $q_{a}>0$ and that one version is free, all consumers always purchase one of the media firm's products (the market is covered). Hence, the media firm has no incentives to invest in increasing $v$ if it is advertising-based or introduces the option to pay to remove advertisements. Moreover, our setup does unfortunately not allow us to consider the question about how paying to remove advertisements affects the variety of content supplied by the media firm, which is another important issue with regards to welfare discussions in the media literature. In a related paper, Anderson and Gans (2008) show, with respect to ad-avoidance technologies, that a media firm's content quality might be of lower quality and be tailored to appeal to a wider range of consumers (less variety) if consumers can use advertising avoidance technologies. However, in our setting, the media firm profits from ad-avoiders which they do not in Anderson and Gans (2008). Hence, it is not clear that their results transfer to our setting. Unfortunately, extending the current model to relax the assumption of market coverage and to study these issues has proven to be less than straightforward.

\section{Conclusion}

In this paper, we have analyzed a monopolist media firm's incentives to introduce an option to pay to remove advertisements from an otherwise advertisement-based product. The monopolist will introduce the option if the disutility from advertisements experienced by consumers is sufficiently high in relation to advertisers' profit margins from reaching users.

\footnotetext{
${ }^{17}$ Alternatively, only the profit margin could be dependent on $\theta$ and the pricing problem could be bypassed.
} 
The media firm trades off revenue from paying consumers with the potential advertising revenue that can be earned by mediating those consumers to advertisers. Because the free advertising-based product cannibalizes on the sales of a pay version without advertisements, it is shown that the media firm optimally increases advertising quantity in the free version when the option to pay to remove advertisements is introduced. Increasing advertising quantity is a more effective way of reducing the perceived quality of the free version, if consumers' disutility from advertisements is higher. Hence, advertising quantity in the free version may be increasing in the disutility caused by an advertisement.

Regarding the welfare implications of introducing the option to pay, we show that consumer welfare decreases, while media firm profits and advertiser profits increase. Consumer welfare decreases because consumers using the free version see more advertisements, and consumers paying to remove pay a price that causes more disutility than what advertisements would have caused had the option to pay not been available.

These results give two empirical predictions. First, the observed advertising quantity should be higher if the option to pay to remove advertisements is available. Second, advertisements should be more annoying and intrusive if the option to pay to remove advertisements is present. Empirically testing these predictions would be interesting as they seem to be in line with casual observations.

\section{Appendix}

\section{A Proofs}

\section{A.1 Proof of Lemma 1}

The first-order condition is given by $1-\frac{2 p_{a}}{s N}=0$ which gives $p_{a}=\frac{s N}{2}$. The second-order condition is satisfied since $-\frac{2}{s N}<0$. Substituting $p_{a}=\frac{s N}{2}$ in $a\left(p_{a}\right)$ and $\Pi_{A}\left(p_{a}\right)$ gives $a_{a}=\frac{1}{2}$ and $\Pi_{A}=\frac{N s}{4}$.

\section{A.2 Proof of Proposition 1}

Assume the solution to be interior so that none of the constraints are binding. Taking the first-order conditions and solving the resulting simultaneous equation system yields two solutions for $\left\{p_{c}, p_{a}\right\}$ given by $\left\{\frac{(s+\gamma)^{2}}{9 s}, \frac{1}{9} N\left(s-\gamma+\frac{2 s^{2}}{\gamma}\right)\right\}$ and $\left\{0, N \frac{s(s+\gamma)}{\gamma}\right\}$. The determinants of the principal minors evaluated at each solution point are $\left\{\frac{2}{3} N\left(\frac{9}{s+\gamma}-\frac{1}{s}-\frac{7}{\gamma}\right), \frac{3}{s^{2}}\right\}$ and $\left\{2 N\left(\frac{1}{s+\gamma}-\frac{2}{\gamma}\right),-\frac{1}{s^{2}}\right\}$. They should alternate in sign such that the first is non-positive and the second is non-negative for the solution to be a maximum. Since $-\frac{1}{s^{2}}<0$, the optimum cannot be the solution characterized by $\left\{0, N \frac{s(s+\gamma)}{\gamma}\right\}$. The second solution satisfies the second-order conditions if $\frac{2}{3} N\left(\frac{9}{s+\gamma}-\frac{1}{s}-\frac{7}{\gamma}\right)<0$. Denote the candidate solution by stars. Use $n\left(p_{c}^{*}, p_{a}^{*}\right)$ and $a\left(p_{c}^{*}, p_{a}^{*}\right)$ to obtain expressions for demand in terms of the exogenous variables. This gives $n^{*}=\frac{s+\gamma}{3 \gamma}$ and $a^{*}=\frac{s+\gamma}{3 s}$. It is now apparent that the solution is an interior optimum only if $\left.\frac{s}{\gamma} \in\right] \frac{1}{2}, 2[$, since otherwise the prices are not consistent with demand configurations in the range $N n \in[0, N]$ and $a \in[0,1]$. Since $\frac{2}{3} N\left(\frac{9}{s+\gamma}-\frac{1}{\gamma}-\frac{7}{\gamma}\right)<0$ for this range, the candidate solution is the optimum. At the boundary where $\frac{s}{\gamma}=2$, the problem 
reduces to that where only the advertising-based version is offered $\left(n=1\right.$ and $\left.a=\frac{1}{2}\right)$. At the other boundary $\frac{s}{\gamma}=\frac{1}{2}$, all advertisers buy ad-space $(a=1)$ so that the lower quality version has the quality $q_{a}=v-\gamma$. Half of the consumers pay to remove advertisements $\left(n=\frac{1}{2}\right)$. For $\left.\frac{s}{\gamma} \in\right] \frac{1}{2}, 2\left[\right.$, total profits are increasing in $\gamma$ and $s$, since $\frac{\partial \Pi_{F+A}}{\partial \gamma}=\frac{N(2 \gamma-s)(\gamma+s)^{2}}{27 \gamma^{2} s}>$ 0 and $\frac{\partial \Pi_{F+A}}{\partial s}=\frac{N(2 s-\gamma)(\gamma+s)^{2}}{27 \gamma s^{2}}>0$. Profits can be split into profits from consumers and profits from advertisers. Profits from consumers are given by $\Pi_{A+F}^{C}=N \frac{(2 \gamma-s)(\gamma+s)^{2}}{27 \gamma s}$ and profits from advertisers are given by $\Pi_{A+F}^{A}=N \frac{(2 s-\gamma)(\gamma+s)^{2}}{27 \gamma s}$. Then, it is the case that $\frac{\partial \Pi_{A+F}^{C}}{\partial \gamma}=N \frac{4 \gamma^{3}+3 \gamma^{2} s+s^{3}}{27 \gamma s^{2}}>0, \frac{\partial \Pi_{A+F}^{C}}{\partial s}=-N \frac{2\left(\gamma^{3}+s^{3}\right)}{27 \gamma^{2} s}<0, \frac{\partial \Pi_{A+F}^{A}}{\partial \gamma}=-N \frac{2\left(\gamma^{3}+s^{3}\right)}{27 \gamma^{2} s}<0$ and $\frac{\partial \Pi_{A+F}^{A}}{\partial s}=N \frac{4 s^{3}+3 \gamma s^{2}+\gamma^{3}}{27 \gamma s^{2}}>0$. For $\left.\frac{s}{\gamma} \in\right] \frac{1}{2}, 2$ [, advertising quantity is $a=\frac{s+\gamma}{3 s}$. This is larger than $\frac{1}{2}$, which is the advertising quantity when the media firm is entirely advertising-based (by lemma 1).

\section{A.3 Proof of Proposition 2}

The consumer and advertiser surplus if the media firm allows consumers to pay to remove advertisements is given by:

$$
\begin{aligned}
C S_{F+A}^{A} & =N \int_{0}^{\theta_{c}^{*}} \theta\left(v-a^{*}\right) d \theta=N \frac{(s-2 \gamma)\left(2 \gamma(s+v)^{2}-3 s v(4 \gamma+s)\right.}{54 s \gamma^{2}} \\
C S_{F+A}^{F} & =N \int_{\theta_{c}^{*}}^{1} \theta v-p_{c}^{*} d \theta=N \frac{(\gamma+s)^{2}(3 s v-\gamma(\gamma+s))}{54 s \gamma^{2}} \\
A S_{F+A} & =\int_{\sigma_{a}^{*}}^{1} \sigma s N n^{*}-p_{a}^{*} d \sigma=N \frac{(s+\gamma)^{3}}{54 s \gamma}
\end{aligned}
$$

where $\theta_{c}^{*}=\frac{s+\gamma}{3 \gamma}, \sigma^{*}=\frac{2 s-\gamma}{3 s}, a^{*}=\frac{1}{3}+\frac{\gamma}{3 s}, p_{c}^{*}=\frac{(s+\gamma)}{9 s}$ and $p_{a}^{*}=N \frac{1}{9}\left(s+\frac{2 s}{\gamma}-\gamma\right)$. The surplus for these consumers under the ad-based business model, i.e. with $\theta_{c}^{*}=\frac{s+\gamma}{3 \gamma}, \sigma^{*}=\frac{2 s-\gamma}{3 s}, a^{*}=\frac{1}{2}$ and $p_{a}^{*}=N \frac{s}{2}$, would have been:

$$
\begin{aligned}
C S_{A^{\prime}}^{A} & =N \int_{0}^{\theta_{c}^{*}} \theta\left(v-a^{*}\right) d \theta=N \frac{(g+s)^{2}(2 v-\gamma)}{36 \gamma^{2}} \\
C S_{A^{\prime}}^{F} & =N \int_{\theta_{c}^{*}}^{1} \theta\left(v-a^{*}\right) d \theta=N \frac{(2 \gamma-s)(4 \gamma+s)(2 v-\gamma)}{36 \gamma^{2}}
\end{aligned}
$$

where the sum of these two is $N \frac{(2 v-\gamma)}{4}$ and the total advertiser surplus under the ad-based business model is $A S_{A}=N \frac{s}{8}$. Consider the following differences in surplus. Let $\triangle C S^{F}=$ $C S_{F+A}^{F}-C S_{A^{\prime}}^{F}$ denote the difference in surplus for consumers who choose to pay to remove advertisements when this option is available to them. Let $\Delta C S^{A}=C S_{F+A}^{A}-C S_{A^{\prime}}^{A}$ be the difference in surplus for consumers who still choose to use the advertising based version when the option to pay to remove advertisements is available. Denote the difference in advertiser surplus by $\Delta A S=A S_{F+A}-A S_{A}$ and the difference in firm profits by $\Delta \Pi=\Pi_{F+A}-\Pi_{A}$. 
Let $r$ be the ratio $\frac{s}{\gamma}$. Then, the differences in surplus can be expressed as

$$
\begin{aligned}
\Delta C S^{F} & =\frac{(r-2)^{3} N \gamma}{108 r} \\
\Delta C S^{A} & =\frac{(r-2)(1+r)^{2} N \gamma}{108 r} \\
\Delta A S & =\frac{(r-2)^{2}(1+4 r) N \gamma}{216 r} \\
\Delta \Pi & =\frac{(r-2)^{2}(1+4 r) N \gamma}{108 r} .
\end{aligned}
$$

The difference in advertiser surplus and firm profits is positive for $r \in] \frac{1}{2}, 2[$. The difference in consumer surplus is negative for both consumer segments. The effect on total welfare is equal to $\Delta W=\Delta A S+\Delta C S^{F}+\Delta C S^{A}+\Delta \Pi=\frac{1}{216 r} M \gamma(r-2)(4+r(16 r-25))$. The effect on total welfare is ambiguous and depends on $\operatorname{sign}\{4+r(16 r-25)\}$.

\section{A.4 Proof of Lemma 2}

The first-order condition is given by $N\left(1-\frac{2 p_{c}}{v}\right)=0$ which gives $p_{c}=\frac{v}{2}$. The second-order condition is satisfied since $-N \frac{2}{v}<0$. Substituting $p_{c}=\frac{v}{2}$ in $\Pi_{F}\left(p_{c}\right)$ gives $\Pi_{F}=N \frac{v}{4}$.

\section{A.5 Proof of Proposition 3}

Through the proof of proposition $1, \Pi_{F} \geq \Pi_{A+F}>\Pi_{A}$ if $\frac{s}{\gamma} \leq \frac{1}{2}$ since $\gamma \leq v$. This gives the first part of the proposition. If $\left.\frac{s}{\gamma} \in\right] \frac{1}{2}, 2\left[\right.$, then $\Pi_{A+F}>\Pi_{A}$ by the proof of proposition 1 but it may be that $\Pi_{F} \geq \Pi_{A+F}$. This is the case for $v \geq v^{*}$ where $v^{*}$ is such that $\Pi_{F}-\Pi_{A+F}=N \frac{v^{*}}{4}-N \frac{(\gamma+s)^{2}}{27 \gamma s}=0$. This gives the second part. If $\frac{s}{\gamma} \geq 2$, then $\Pi_{A}>\Pi_{A+F}$ by the proof of proposition 1 but it may be that $\Pi_{F} \geq \Pi_{A}$. This is the case for $v \geq v^{* *}$ where $v^{* *}$ is such that $\Pi_{F}-\Pi_{A}=N \frac{v^{* *}}{4}-N \frac{s}{4}=0$.

\section{References}

[1] Anderson, S. and Coate, S., 2005. Market Provision of Broadcasting: A Welfare Analysis. Review of Economic Studies 72, pp. 947-972.

[2] Anderson, S. and Gans, J., 2008. Tivoed: The effects of ad-avoidance technologies on broadcaster behaviour. Mimeo available at http://www.mbs.edu/jgans/.

[3] Armstrong, M., 2006. Competition in Two-sided Markets, RAND Journal of Economics 37, pp. 668-691.

[4] Bagwell, K., 2007. The economic analysis of advertising. Handbook of Industrial Organization Volume 3, pp 1701-1844.

[5] Caillaud, B. and Jullien, B., 2003. Chicken \& egg: Competition among intermediation service providers. RAND Journal of Economics 24, pp. 309-328. 
[6] Chiang, R. and Spatt, C., 1982. Imperfect price discrimination and welfare. Review of Economic Studies 49, pp. 155-181.

[7] Crampes, C., Haritchabalet, C. and Jullien, B., 2005. Advertising, Competition and Entry in Media Industries, CESifo Working Paper no 1591.

[8] Deneckere, R. and McAfee P., 1996. Damaged goods. Journal of Economics and Management Strategy 5, pp. 149-174.

[9] Gabszewicz, J., Laussel, D. and Sonnac, N., 2004. Programming and advertising competition in the broadcasting industry. Journal of Economics and Management Strategy 13, pp. 657-669.

[10] Greenstein, S. and Ramey, G., 1998. Market Structure, Innovation and Vertical Product Differentiation. International Journal of Industrial Organization 16, pp. 285-311.

[11] Hansen, C. T. and Kyhl, S., 2001. Pay-per-view broadcasting of outstanding events: consequences of a ban. International Journal of Industrial Organization 19, pp. 589609.

[12] Holden, S., 1993. Network or pay-per-view? Economics Letters 43, pp. 59-64.

[13] Mussa, M. and Rosen, S., 1978. Monopoly and product quality. Journal of Economic Theory 18, pp. 301-317.

[14] Prasad, A., Mahajan,V. and Bronnenberg, B., 2003. Advertising versus pay-per-view in electronic media. International Journal of Research in Marketing 20, pp. 13-30.

[15] Rochet, J.-C. and Tirole, J., 2003. Platform competition in two-sided markets. Journal of the European Economic Association 1, pp. 990-1029.

[16] Salop, S., 1977. The noisy monopolist: Imperfect information, price dispersion and price discrimination. The Review of Economic Studies 44, pp. 393-406.

[17] Shaked, A. and Sutton, J., 1982. Relaxing Price Competition Through Product Differentiation. The Review of Economic Studies 49, pp 3-13.

[18] Varian, H., 2001. Versioning information goods. Internet Publishing and Beyond: The Economics of Digital Information and Intellectual Property. ed. by B. Kahin and H. R. Varian. MIT Press.

[19] Wilbur, K., 2008a. How the Digital Video Recorder (DVR) Changes Traditional Television Advertising. Journal of Advertising 37 pp. 143-149.

[20] Wilbur, K., 2008b. A Two-Sided, Empirical Model of Television Advertising and Viewing Markets. Marketing Science 27, pp. 356-378. 